\title{
A pulse amplitude modulation scheme based on in-line semiconductor optical amplifiers (SOAs) for optical soliton systems
}

\author{
Aadel M. Alatwi ${ }^{1}$, Ahmed Nabih Zaki Rashed ${ }^{2}$ \\ ${ }^{1}$ Electrical Engineering Department, Faculty of Engineering, University of Tabuk, Tabuk, Saudi Arabia \\ ${ }^{2}$ Electronics and Electrical Communications Engineering Department, Menoufia University, Egypt
}

\begin{tabular}{|c|c|}
\hline Article Info & ABSTRACT \\
\hline Article history: & The objective of this work is to simulate a pulse amplitude modulation \\
\hline Received Feb 20, 2020 & $\begin{array}{l}\text { (PAM) scheme based on in-line semiconductor optical amplifiers for optical } \\
\text { soliton systems. The max. power for soliton systems, based on various }\end{array}$ \\
\hline Revised May 17, 2020 & bits/symbol PAM modulation schemes after a fiber length of $100 \mathrm{~km}$, is \\
\hline Accepted Jun 5, 2020 & $\begin{array}{l}\text { simulated and clarified. In addition to the max. Q factor for soliton systems, } \\
\text { PAM modulation schemes with various in-line SOA injection currents and a }\end{array}$ \\
\hline Keywords: & The total electrical power after photo-detectors for soliton systems, based on \\
\hline $\begin{array}{l}\text { Electrooptic modulators } \\
\text { PAM } \\
\text { SOA injection current } \\
\text { Soliton pulse }\end{array}$ & $\begin{array}{l}\text { PAM modulation schemes with various in-line SOA injection currents and a } \\
\text { fiber length of } 100 \mathrm{~km} \text {, is also simulated and clarified in the results. } \\
\text { The study emphasizes that the higher the SOA injection current, the higher } \\
\text { the electrical power and the lower the Q factor that can be achieved in the } \\
\text { soliton system. }\end{array}$ \\
\hline
\end{tabular}

This is an open access article under the CC BY-SA license.

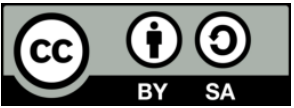

\section{Corresponding Author:}

Ahmed Nabih Zaki Rashed

Faculty of Electronic Engineering

Menoufia University

Gamal Abd El-Nasir, Qism Shebeen El-Kom

Shibin el Kom, Menofia Governorate, Egypt

E-mail: ahmed_733@yahoo.com

\section{RELATED WORKS}

Networks operate at bit rates of the order of $100 \mathrm{Mb} / \mathrm{s}$, due to optical media. Network standards with still higher bit rates (of the order of $\mathrm{Gb} / \mathrm{s}$ ) have been developed, e.g., fiber channel standard (FCS) and highperformance parallel interface (HIPPI) [1-8]. HIPPI uses multiple parallel links, each of which operates at bit rates of the order of $100 \mathrm{Mb} / \mathrm{s}$ [9-13]. The parallel links can use an electrical cable for shorter distances (a few meters) or optical fiber for longer distances (a few kilometers). Further increases in broadcast networks' capacity for efficient utilization of optical fiber have been hindered by an electronic bottleneck. Transmitters and receivers become extremely costly with an increase in bit rates above Gb/s [14-20].

At high bit rates, optical multiplexing and demultiplexing techniques are used to attain largecapacity networks. Large-capacity switched optical networks are also possible [21-28]. Soliton is an isolated, particle-like wave that offers a solution in certain equations for propagating and acquiring when two solitary waves do not change their form after collision and, subsequently, travel for considerable distances [29-35]. 


\section{MODEL DESCRIPTION AND RESEARCH METHOD}

Figure 1 shows the proposed soliton system, based on inline SOAs with pulse amplitude modulation technique. The user-defined sequence generators are responsible for the generation of bit streams. The bit stream sequences are modulated through an electrical PAM modulator. The optical Sech pulse generators are responsible for generating soliton pulses. The basic concept in soliton systems is the balance between dispersion effects and nonlinearity effects. The nonlinear effects are the reason for the pulse shrinking, but the dispersion effects are the reason for the pulse broadening. So, when the two effects are balanced, the result is a balanced soliton pulse that can be propagated for max. transmission distances.

The soliton pulse frequency is $193.1 \mathrm{THz}$ with power of $100 \mathrm{~mW}$. The LiNbO3 electro-optic modulators have three inputs: two electrical modulated signals and one soliton optical pulse. The electrooptic modulated signal is injected into the fiber length of $100 \mathrm{~km}$. The signal power is measured through optical spectrum analyzers. The signal is amplified, and signal processing can be applied through travelingwave SOA. The amplified signal is eliminated from the ripples through Gaussian light filters. The optical receiver is APD photo-detectors, which are responsible for converting light signals into electrical signal form. The total electrical power, max. Q factor, and min. BER can be measured through electrical power meter and eye diagram analyzers, respectively.

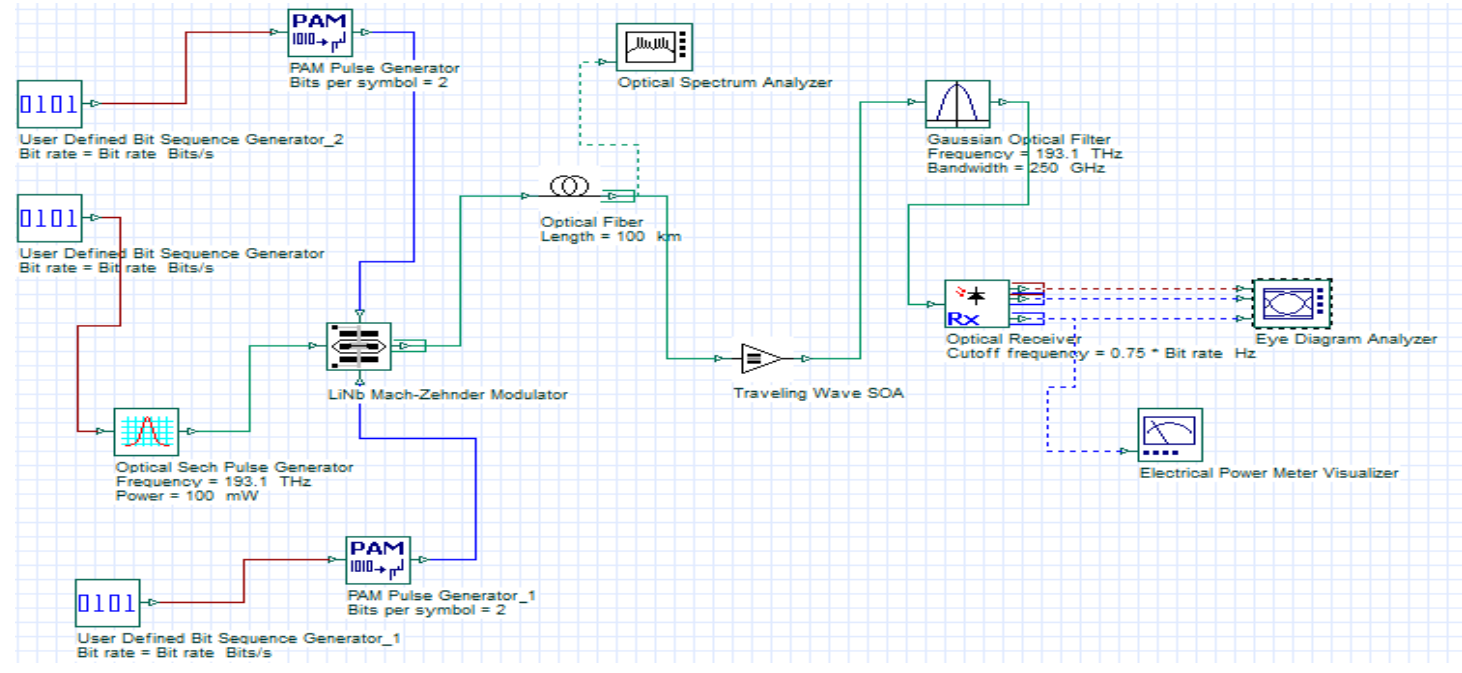

Figure 1. Proposed model description for this study

\section{PERFORMANCE ANALYSIS WITH DISCUSSIONS}

We have simulated the max. power for soliton systems based on various bits/symbol in a PAM modulation scheme after a fiber length of $100 \mathrm{~km}$. Also, the max. Q factor for the soliton PAM modulation scheme is shown using in-line SOA, based on various injection currents at a fiber length of $100 \mathrm{~km}$. Moreover, the total electrical power for the soliton PAM modulation scheme is demonstrated using in-line SOA based on various injection currents at a fiber length of $100 \mathrm{~km}$. All the results are assured, based on the variable in Table 1.

Table 1. Basic parameters for proposed model

\begin{tabular}{cc}
\hline Variables & Values/units \\
\hline Pulse frequency & $193.1 \mathrm{THz}$ \\
Pulse power & $100 \mathrm{~mW}$ \\
Fiber length & $100 \mathrm{~km}$ \\
SOA injection current & $30 \mathrm{~mA}-100 \mathrm{~mA}$ \\
Modulator extinction ratio & $20 \mathrm{~dB}$ \\
Modulator bias voltage & $4 \mathrm{~V}$ \\
Modulator insertion loss & $5 \mathrm{~dB}$ \\
Optical filter bandwidth & $250 \mathrm{GHz}$ \\
Optical filter frequency & $193.1 \mathrm{THz}$ \\
Optical receiver type & $\mathrm{APD}$ \\
APD gain & 10 \\
APD responsitivity & $0.9 \mathrm{~A} / \mathrm{W}$ \\
\hline
\end{tabular}


Figures 2-6 show the max. power for soliton systems based on various bits/symbol in a PAM modulation scheme after a fiber length of $100 \mathrm{~km}$. Figure 2 clarifies the max. power for a soliton system based on a 2 bits/symbol PAM modulation scheme after a fiber length of $100 \mathrm{~km}$. Where the max. soliton power is $-9.726 \mathrm{dBm}$, the noise soliton power is $-104.299 \mathrm{dBm}$. Figure 3 indicates the max. power for a soliton system based on a 4 bits/symbol PAM modulation scheme after a fiber length of $100 \mathrm{~km}$. Where the max. soliton power is $-9.66482 \mathrm{dBm}$, the noise soliton power is $-104.302 \mathrm{dBm}$. Figure 4 demonstrates the max. power for a soliton system based on an 8 bits/symbol PAM modulation scheme after a fiber length of $100 \mathrm{~km}$. Where the max. soliton power is $-9.25334 \mathrm{dBm}$, the noise soliton power is $-104.321 \mathrm{dBm}$.

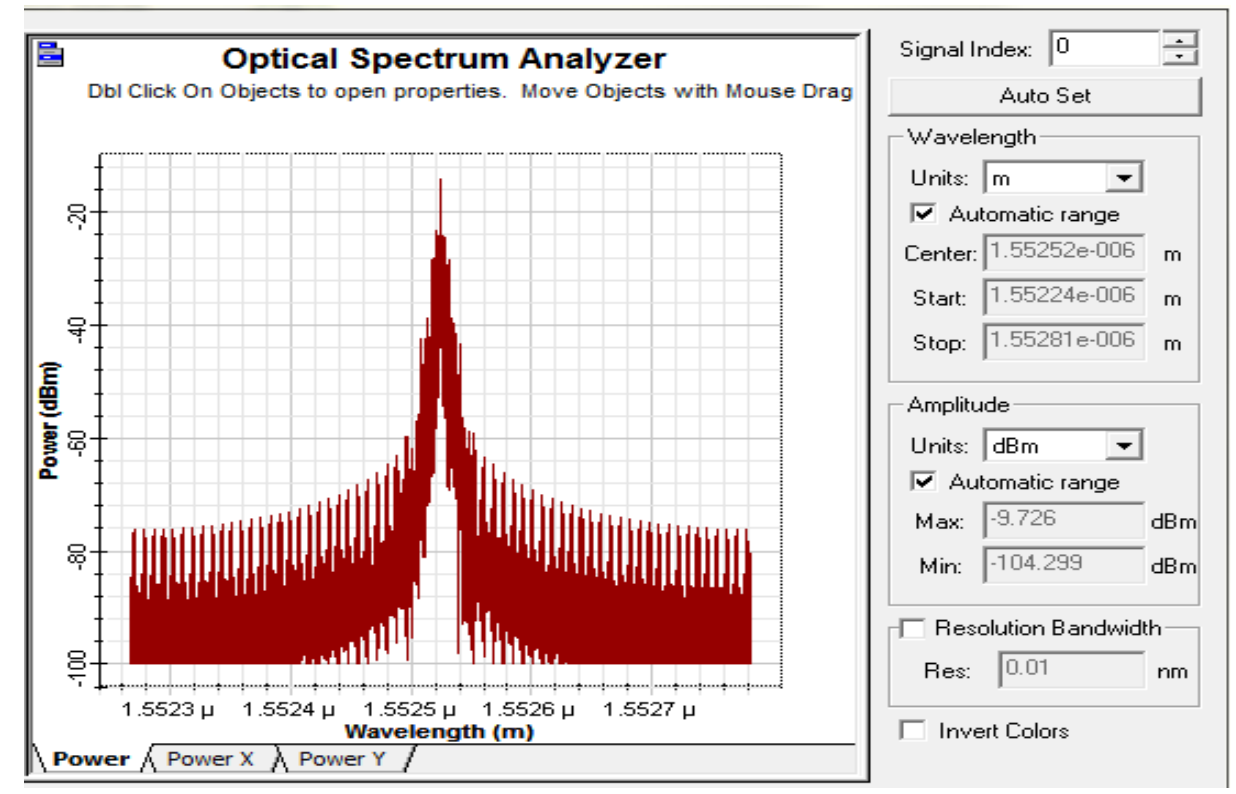

Figure 2. Max. power for soliton system based 2 bits/symbol PAM modulation scheme after fiber length of $100 \mathrm{~km}$

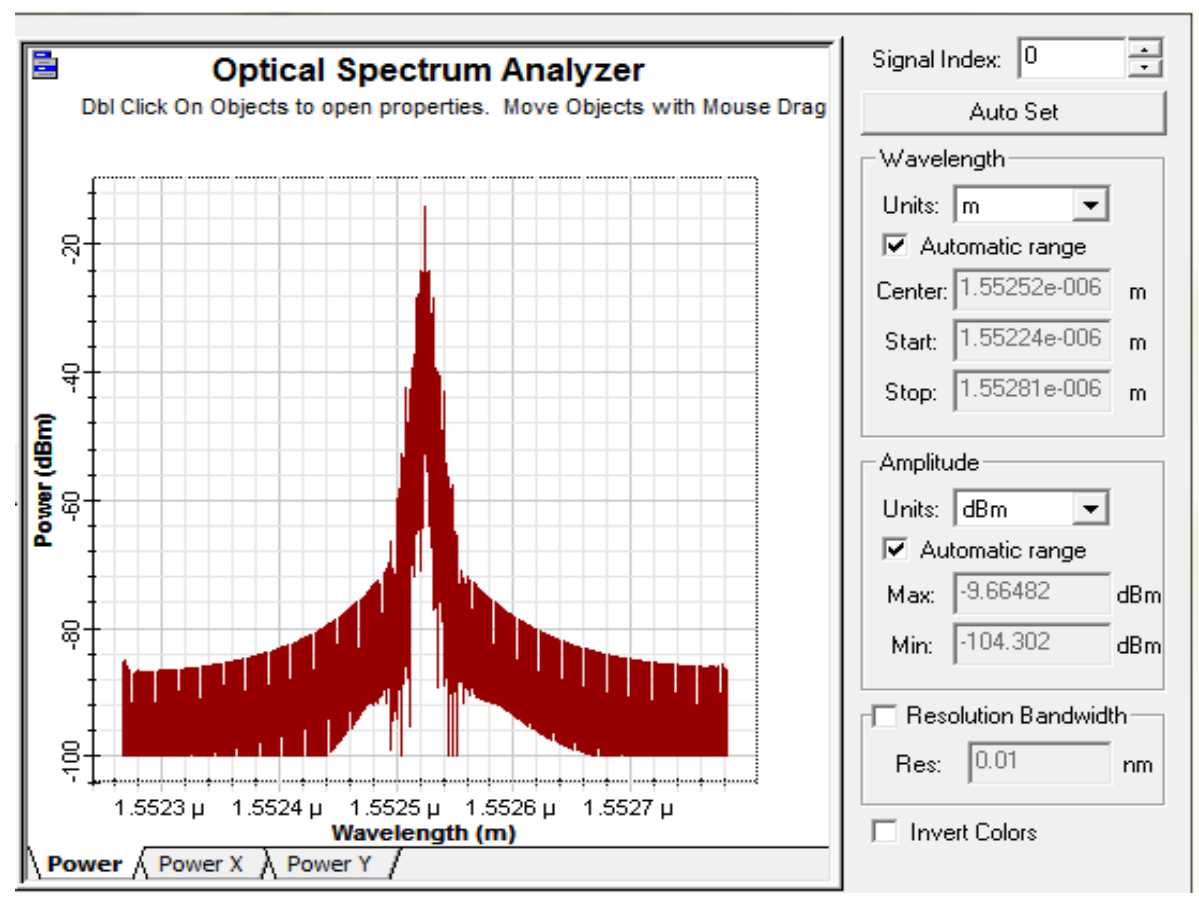

Figure 3. Max. power for soliton system based 4 bits/symbol PAM modulation scheme after fiber length of $100 \mathrm{~km}$ 

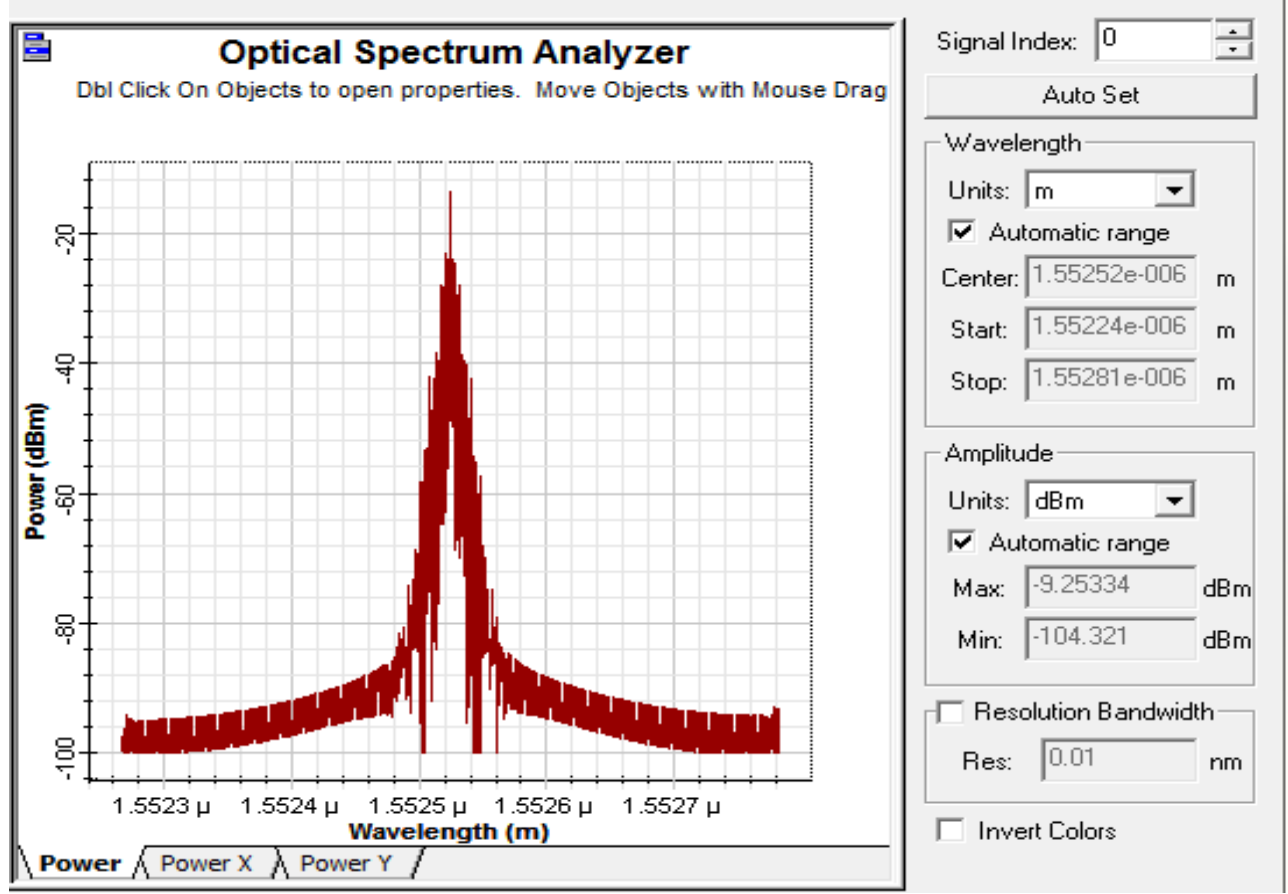

Figure 4. Max. power for soliton system based 8 bits/symbol PAM modulation scheme after fiber length of $100 \mathrm{~km}$
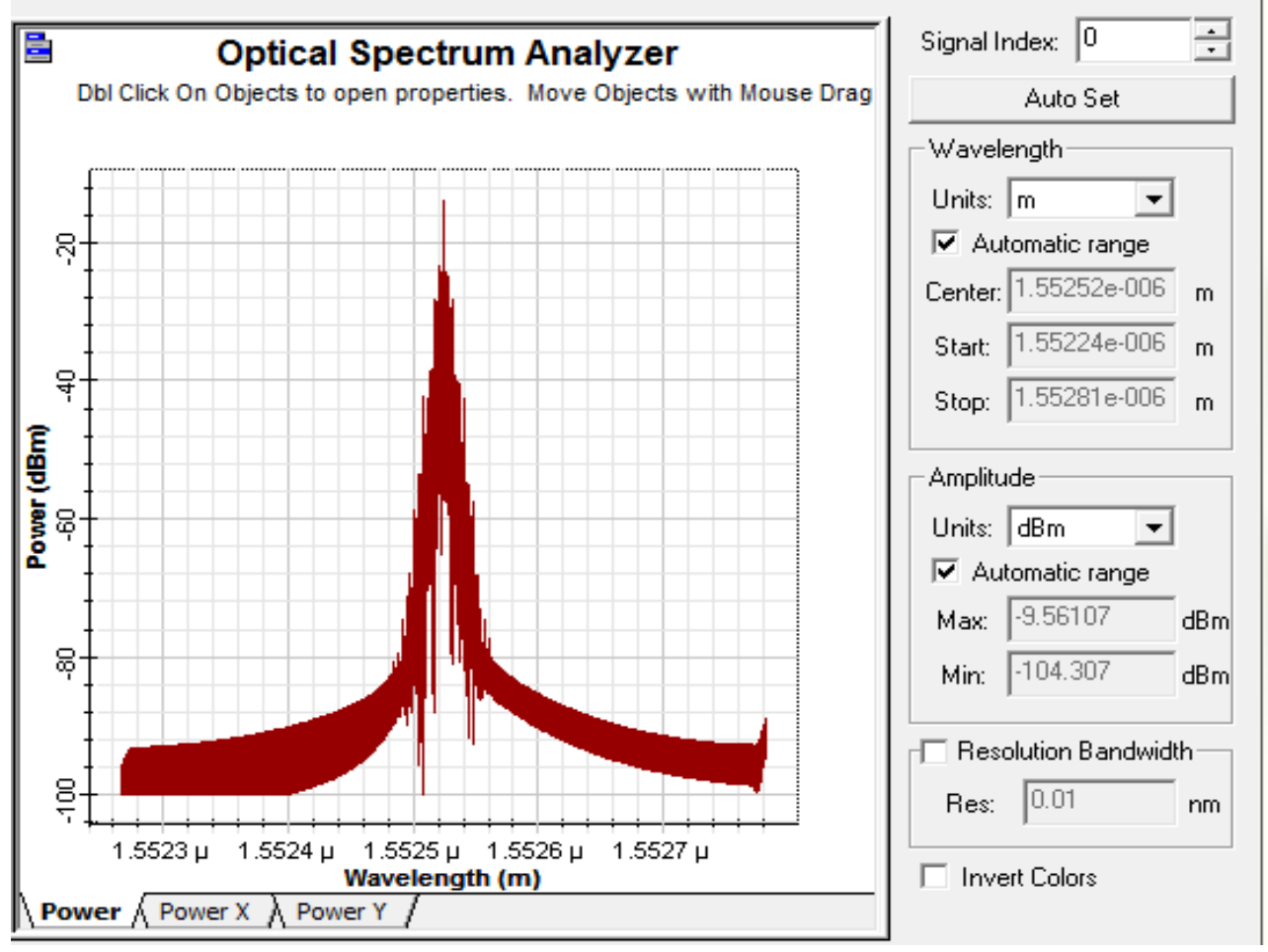

Figure 5. Max. power for soliton system based 16 bits/symbol PAM modulation scheme after fiber length of $100 \mathrm{~km}$ 

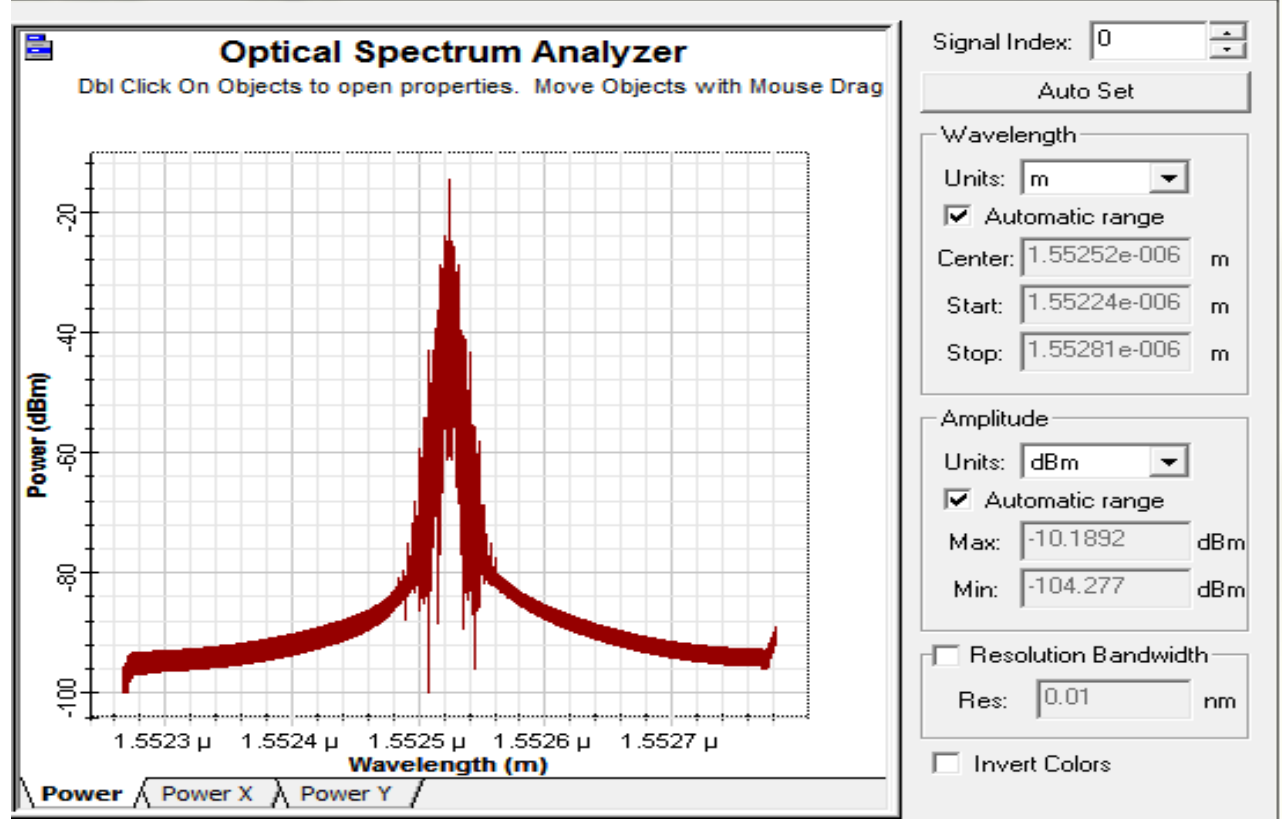

Figure 6. Max. power for soliton system based 32 bits/symbol PAM modulation scheme after fiber length of $100 \mathrm{~km}$

Figure 5 shows the max. power for a soliton system based on a 16 bits/symbol PAM modulation scheme after a fiber length of $100 \mathrm{~km}$. Where the max. soliton power is $-9.56107 \mathrm{dBm}$, the noise soliton power is $-104.307 \mathrm{dBm}$. Figure 6 illustrates the max. power for a soliton system based on a $16 \mathrm{bits} / \mathrm{symbol}$ PAM modulation scheme after a fiber length of $100 \mathrm{~km}$. Where the max. soliton power is $-10.1892 \mathrm{dBm}$, the noise soliton power is $-104.277 \mathrm{dBm}$. The soliton peak power degrades with an increase of bits per symbol, based on the PAM modulation scheme. Figure 7 illustrates the max. Q factor for a soliton PAM modulation scheme based on an in-line SOA injection current of $30 \mathrm{~mA}$ and a fiber length of $100 \mathrm{~km}$. Where the max. Q factor is 11.31 , the min. BER is $3.49 \times 10^{-30}$. Figure 8 demonstrates the total electrical power for a soliton PAM modulation scheme based on an in-line SOA injection current of $30 \mathrm{~mA}$ and a fiber length of $100 \mathrm{~km}$. The total electrical power is measured at a value of $2.556 \mathrm{~mW}(4.075 \mathrm{dBm})$.
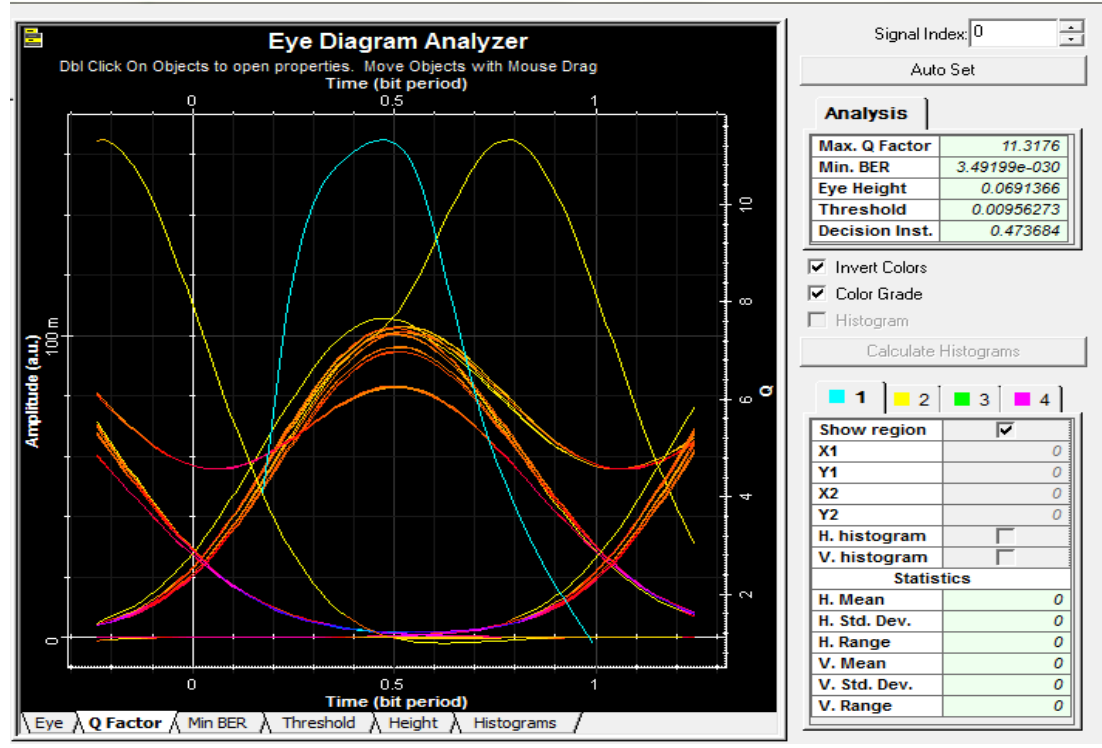

Figure 7. Max. Q Factor for soliton PAM modulation scheme based in line SOA injection current of $30 \mathrm{~mA}$ and fiber length of $100 \mathrm{~km}$ 


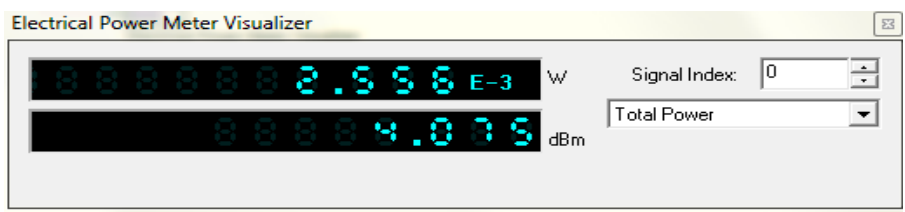

Figure 8. Total electrical power for soliton PAM modulation scheme based in line SOA injection current of $30 \mathrm{~mA}$ and fiber length of $100 \mathrm{~km}$

Figure 9 shows the max. Q factor for a soliton PAM modulation scheme based on an in-line SOA injection current of $65 \mathrm{~mA}$ and a fiber length of $100 \mathrm{~km}$. Where the max. Q factor is 9.24, the min. BER is $1.105 \times 10^{-20}$. Figure 10 illustrates the total electrical power for a soliton PAM modulation scheme based on an in-line SOA injection current of $65 \mathrm{~mA}$ and a fiber length of $100 \mathrm{~km}$. The total electrical power is measured at a value of $51.009 \mathrm{~mW}(17.076 \mathrm{dBm})$.
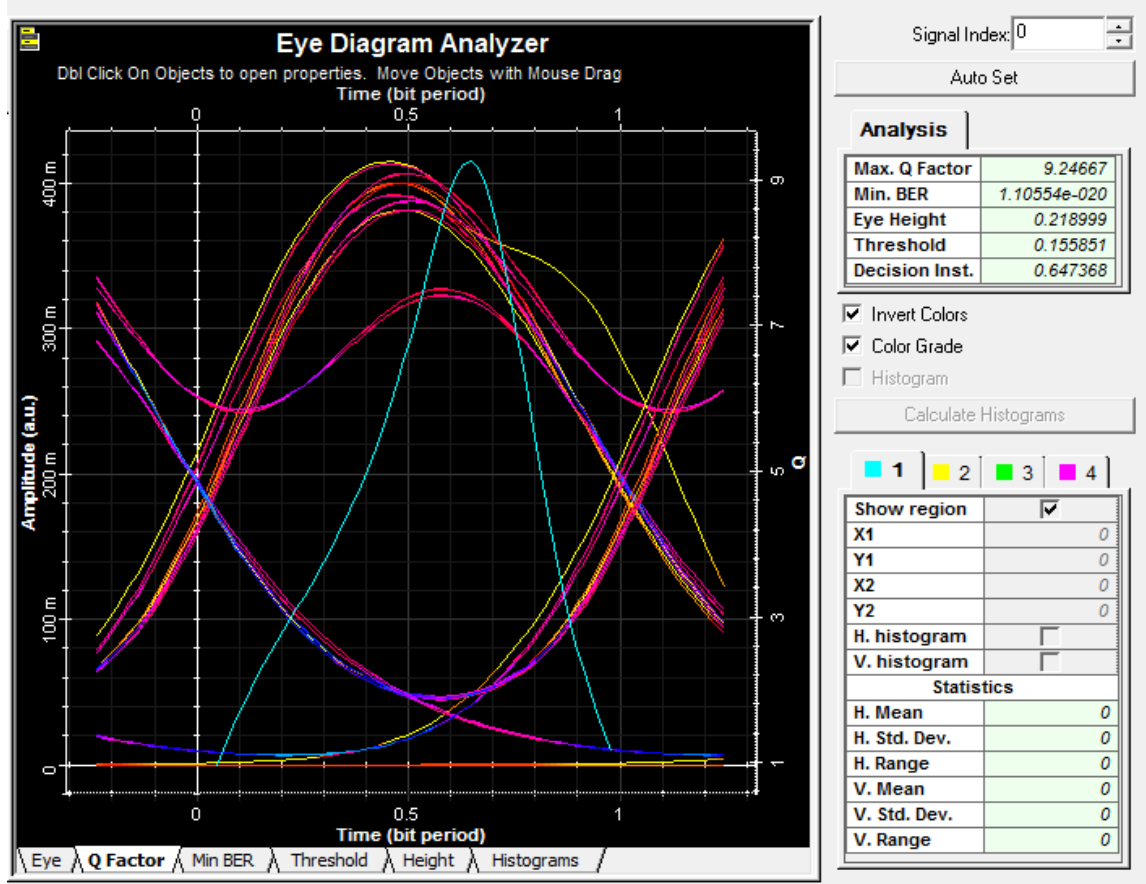

Figure 9. Max. Q Factor for soliton PAM modulation scheme based in line SOA injection current of $65 \mathrm{~mA}$ and fiber length of $100 \mathrm{~km}$

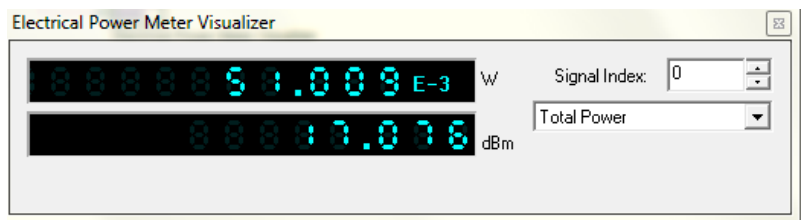

Figure 10. Total electrical power for soliton PAM modulation scheme based in line SOA injection current of $65 \mathrm{~mA}$ and fiber length of $100 \mathrm{~km}$

Figure 11 shows the max. Q factor for a soliton PAM modulation scheme based on an in-line SOA injection current of $100 \mathrm{~mA}$ and a fiber length of $100 \mathrm{~km}$. Where the max. Q factor is 5.97, the min. BER is $1.142 \times 10^{-9}$. Figure 12 indicates the total electrical power for a soliton PAM modulation scheme based on an in-line SOA injection current of $100 \mathrm{~mA}$ and a fiber length of $100 \mathrm{~km}$. The total electrical power is measured at a value of $95.9 \mathrm{~mW}(19.818 \mathrm{dBm})$. 

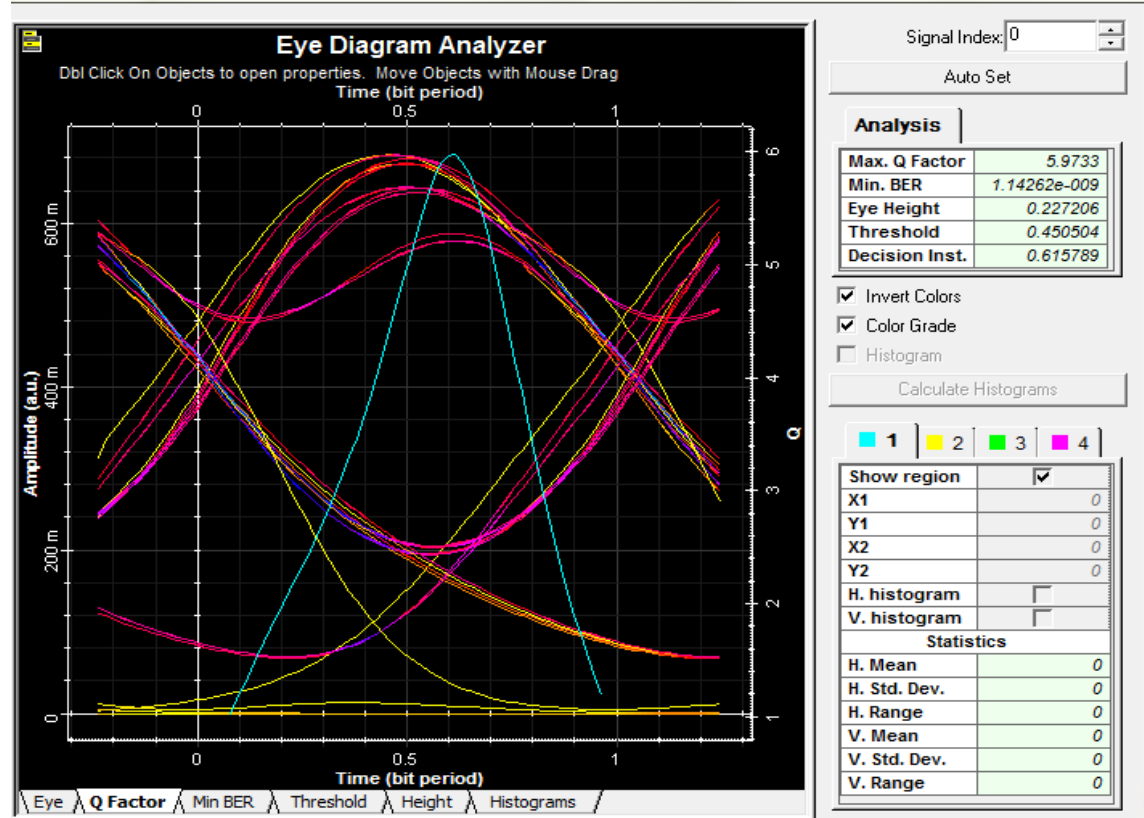

Figure 11. Max. Q Factor for soliton PAM modulation scheme based in line SOA injection current of $100 \mathrm{~mA}$ and fiber length of $100 \mathrm{~km}$

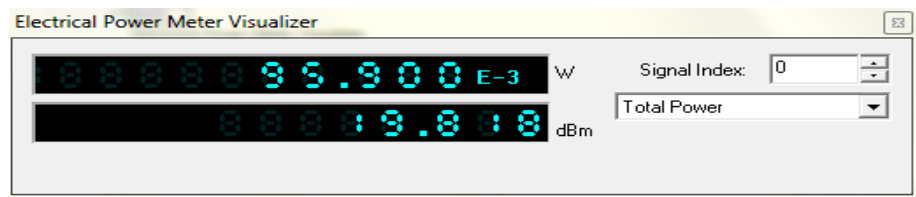

Figure 12. Total electrical power for soliton PAM modulation scheme based in line SOA injection current of $65 \mathrm{~mA}$ and fiber length of $100 \mathrm{~km}$

\section{CONCLUSION}

We have simulated the total electrical power for a soliton PAM modulation scheme based on an inline SOA for various injection currents at a fiber length of $100 \mathrm{~km}$. This work has demonstrated that the higher the SOA injection current, the higher the electrical power that can be achieved. Also, we have simulated the max. Q factor for the soliton PAM modulation scheme based on various in-line SOA injection currents at a fiber length of $100 \mathrm{~km}$. The study shows that the lower the SOA injection current, the higher the $\mathrm{Q}$ factor that can be achieved. Moreover, the max. power for the soliton system has been clarified based on various bits per symbol PAM modulation schemes at a fiber length of $100 \mathrm{~km}$. The results show that the lower the PAM modulation scheme's bits per symbol, the higher the soliton system power that can be achieved.

\section{REFERENCES}

[1] Ahmed Nabih Zaki Rashed, et al., "20 Gb/s Hybrid CWDM/DWDM for extended reach fiber to the home network applications," Proceedings of the National Academy of Sciences, India Section A: Physical Sciences, vol. 89, no. 4, pp. 653-662, 2019, doi: 10.1007/s40010-018-0526-2.

[2] A. Chandra, et al., "Unified BER and optimum threshold analysis of binary modulations in simple and cascaded rayleigh fading channels with switched combining," International Journal of Communication Systems, vol. 24, no. 2, pp. 153-167, 2011.

[3] A. Maksymiuk, and J. Siuzdak, "Modeling of low frequency modal noise induced by multimode couplers in cascade connections," Optica Applicata, vol. 41, no. 3, pp. 649-660, 2011.

[4] IS Amiri, et al., "Performance enhancement of fiber optic and optical wireless communication channels by using forward error correction codes," Journal of Optical Communications, Dec. 2019, doi: 10.1515/joc-2019-0191.

[5] IS Amiri, et al., "Z Shaped like resonator with crystal in the presence of flat mirror based standing wave ratio for optical antenna systems," Indonesian Journal of Electrical Engineering and Computer Science, vol. 17, no. 3, pp. 1405-1409, 2020, doi: 10.11591/ijeecs.v17.i3.pp1405-1409. 
[6] IS Amiri, et al., "Influence of device to device interconnection elements on the system behavior and stability," Indonesian Journal of Electrical Engineering and Computer Science, vol. 18, no. 2, pp. 843-847, 2020, doi: 10.11591/ijeecs.v18.i2.pp843-847.

[7] F. T. Sheehy, et al., "94 GHz antenna-coupled LiNbO3 electrooptic modulators," IEEE Photonics Technology Letters, vol. 5, no. 3, pp 307-310, 1993.

[8] J. Witzens, et al., "Design of transmission line driven slot waveguide mach-zehnder interferometers and application to analog optical links," Optics Express., vol. 18, no. 16, pp. 16903-16928, 2010.

[9] H. V. Pham, Y. Okamura, "Electrooptic modulators with controlled frequency responses by using nonperiodically polarization reversed structure," Journal of Advances in Optoelectronics, vol. 8, no. 1, pp. 1-8, 2008.

[10] Min Chen, et al., "Advances in multimedia communications," International Journal of Communication Systems, vol. 24, no. 10, pp. 1243-1245, 2011.

[11] Q. TAO, F. Luo, Q. Liang, Z. Wan, X. Song, and X., et al., "Optical switch based on cascaded SOI nonlinear directional coupler," Optica Applicata, vol. 41, no. 3, pp. 669-678, 2011.

[12] T. Kawanishi, et al., "High speed control of lightwave amplitude, phase, and frequency by use of electrooptic effect," IEEE Journal of Selected Topics in Quantum Electronics, vol. 13, no. 1, pp. 79-91, 2007.

[13] H. V. Pham, et al., "Travelling wave electrooptic modulators with arbitrary frequency response utilising non periodic polarization reversal," Electronics Letters, vol. 43, no. 24, pp. 1379-1381, 2007.

[14] H. Tazawa and W. H. Steier, "Analysis of ring resonator based traveling wave modulators," IEEE Photon. Technol. Lett., vol. 18, no. 1, pp. 211-213, 2006.

[15] G. Xu, et al., "Organic electrooptic modulator using transparent conducting oxides as electrodes," Opt. Expr., vol. 13, no. 3, pp. 7380-7385, 2005.

[16] A. Hamadou, "Optical external efficiency calculation for mid infrared quantum cascade laser," Optica Applicata, vol. 41, no. 3, pp. 717-725, 2011.

[17] M. Ghanbarisabagh, et al., "Cyclic prefix reduction for $20.48 \mathrm{~Gb} / \mathrm{S}$ Direct detection optical ofdm transmission over 2560 km of SSMF," International Journal of Communication Systems, vol. 24, no. 11, pp. 1407-1417, 2011.

[18] H. Hu, et al., "Lithium niobate ridge waveguides fabricated by wet etching," IEEE Photonics Technology Letters, vol. 19 , no. 6, pp. 417-419, 2007.

[19] A. Kozanecka, et al., "Electro optic activity of an azopolymer achieved via poling with the aid of silicon nitride insulating layer," Optica Applicata, vol. 41, no. 3, pp. 777-785, 2011.

[20] M. V. Raghavendra, P. H. Prasad, "Estimation of optical link length for multi haul applications," International Journal of Engineering Science and Technology, vol. 2, no.6, pp. 1485-1491, 2010.

[21] S. Praveen Chakkravarthy, et al., "Ultra high transmission capacity based on optical first order soliton propagation systems, ” Results in Physics, vol. 12, pp. 512-513, 2019.

[22] L.M. Johnson, H. V. Roussell, "Reduction of intermodulation distortion in interferometric optical modulators," Optics Letters, vol. 13, no. 10, pp. 928-930, 1988.

[23] IS Amiri, et al., "High-speed transmission circuits signaling in optical communication systems," Journal of Optical Communications, 2019, doi: 10.1515/joc-2019-0197.

[24] IS Amiri, et al., "Technical specifications of the submarine fiber optic channel bandwidth/capacity in optical fiber transmission systems," Journal of Optical Communications, Nov. 2019, doi: 10.1515/joc-2019-0226.

[25] IS Amiri, Ahmed Nabih Zaki Rashed, "Signal processing criteria based on electro-optic filters for fiber optic access transceiver systems," Journal of Optical Communications, 2019, doi: 10.1515/joc-2019-0116.

[26] IS Amiri, et al., "Pump laser automatic signal control for erbium-doped fiber amplifier gain, noise figure, and output spectral power," Journal of Optical Communications, 2019, doi: 10.1515/joc-2019-0203.

[27] Steven K. Korotky, René M. De Ridder, "Dual parallel modulation schemes for low-distortion analog optical transmission," IEEE Journal on Selected Areas in Communications, vol. 8, no. 7, pp. 1377-1381, 1990.

[28] J. F. Lam and G. L. Tangonan, "A novel optical modulation system with enhanced linearization properties," IEEE Photon. Technol. Lett., vol. 3, no. 12, pp. 1102 - 1104, 1991.

[29] William B. Bridges, James H. Schaffner, "Distortion in linearized electrooptic modulators," IEEE Transactions on Microwave Theory and Techniques, vol. 43, no. 9, pp. 2184-2197, 1995.

[30] Ahmed Nabih Zaki Rashed, Mohammed Salah F. Tabbour, "Suitable optical fiber communication channel for optical nonlinearity signal processing in high optical data rate systems" Wireless Personal Communications Journal, Springer Publisher, vol. 97, no. 1, pp. 397-416, 2017.

[31] Ahmed Nabih Zaki Rashed, et al., "Optimum flat gain with optical amplification technique based on both gain flattening filters and fiber bragg grating methods," Journal of Nanoelectronics and Optoelectronics, vol. 13, no. 5, pp. 665-676, 2018.

[32] Ahmed Nabih Zaki Rashed, et al., "The trade off between different modulation schemes for maximum long reach high data transmission capacity optical orthogonal frequency division multiplexing (OOFDM)" Wireless Personal Communications Journal, vol. 101, no. 1, pp. 325-337, Jul. 2018, doi: 10.1007/s11277-018-5690-9.

[33] IS Amiri, et al., "Optical communication transmission systems improvement based on chromatic and polarization mode dispersion compensation simulation management", ptik Journal, vol. 207, 2020, doi: 10.1016/j.ijleo.2019.163853.

[34] Ahmed Nabih Zaki Rashed, et al., "The switching of optoelectronics to full optical computing operations based on nonlinear metamaterials," Results in Physics, vol. 13, 2019, doi: 10.1016/j.rinp.2019.02.088.

[35] IS Amiri, et al., "Comparative simulation study of multi stage hybrid all optical fiber amplifiers in optical communications," Journal of Optical Communications, 2020, doi: 10.1515/joc-2019-0132. 